\title{
Linear Low Density Polyethylene (LLDPE)/Zeolite Microporous Composite Film
}

\author{
Jagannath Biswas, Hyun Kim, and Soonja Choe* \\ Department of Chemical Engineering, Inha University, Incheon 402-751, Korea \\ Patit P. Kundu \\ Department of Chemical Technology, SLIET, Longowal, Punjab-148106, India \\ Young-Hoon Park \\ Department of Polymer Science and Engineering, Suncheon National University, Sunchon 540-742, Korea \\ Dai Soo Lee \\ Department of Chemical Engineering, Chonbuk National University, Jeonju 561-757, Korea
}

Received June 9, 2003; Revised July 28, 2003

\begin{abstract}
The linear low density polyethylene (LLDPE)/zeolite composite using novel inorganic filler, zeolite, is prepared by a conventional compounding procedure using a twin-screw extruder. The observed scanning electron microscopic (SEM) morphology shows a good dispersion and adhesion of zeolite in the LLDPE matrix. The mechanical properties in terms of the Young's modulus, the yield stress, the impact strength, and the elongation at break were enhanced with a successive increment of zeolite content up to $40 \mathrm{wt} \%$. The X-ray diffraction measurement is of supportive for the improved mechanical properties and the complex melt viscosity is as well. Upon applying a certain level of strain on the composites, the dewetting, the air hole formation and its growth are characterized. The dewetting originates around the filler particles at low strain and induces elliptical micropores upon further stretching. The microporosity such as the aspect ratio, the number and the total area of the air holes is also characterized. Thus, the composites loaded $40 \%$ zeolite and $300 \%$ elongation may be applicable for breathable microporous films with improved modulus, impact and yield stress, elongation at break, microporosity and air hole properties.
\end{abstract}

Keywords: LLDPE, zeolite, composite, film, microporosity, air hole.

\section{Introduction}

Thermoplastics have been a choice of matrices for composite materials for decades. Compounding fillers with thermoplastic materials in order to introduce desired properties is a conventional practice. The use of fillers in plastics not only upgrades thermal, mechanical and vast versatile properties, but also reduces the production costs. ${ }^{1-6}$ Most commonly used fillers in making composites include metal oxide, metal powders, carbon black, silica, spherical or fibrous glass, talc, calcite, ${ }^{3,4}$ kaolin, mica etc. ${ }^{7}$ Particulate fillers may have different shapes such as spherical, spheroidal, or cubic. Fillers are directly used in untreated or chemically treated forms prior to compounding with various thermoplastics. There are many beneficial reports on chemically treated fillers that

*e-mail : sjchoe@inha.ac.kr

1598-5032/10/357-11 @2003 Polymer Society of Korea show a better adhesion with polymer matrix than that of untreated ones. 8

In our earlier work on calcite filled thermoplastic composites, the mechanism of the dewetting and air hole formation upon stretching were elaborately explained. ${ }^{10-12}$ By loading $50 \mathrm{wt} \%$ calcite in linear low density polyethylene (LLDPE), some excellent results such as; improved mechanical properties, enhanced heat distortion temperature, augmented complex melt viscosity and good interfacial coexistence between the fillers and the matrix were observed. ${ }^{10}$ In addition, the influence of mixing cycle of $50 \mathrm{wt} \%$ calcite filled LLDPE composite on the various properties were investigated. ${ }^{12}$ The composites prepared by the second mixing yielded better performance in terms of mechanical properties and filler dispersion. ${ }^{12}$ Stress concentration at the surrounding of filler particles is reported to be certainly responsible for dewetting between the filler and the matrix. ${ }^{1}$ Porous films induced by applying certain level of strain can be used in diverse appli- 
cations such as breathable surgical gowns, diaper back sheets, and sports wears etc. ${ }^{13,14}$ Though the existence of dewetting phenomenon in polymeric film is a weak point, yet it will be emphasized in this work.

In general, zeolite is crystalline inorganic polymer possessing an infinitely extending three-dimensional network of $\mathrm{AlO}_{4}$ and $\mathrm{SiO}_{4}$ linked to each other. ${ }^{15}$ In general, porosity of zeolite can be controlled by synthetic methods.

To the best of our knowledge to date, there are little references on zeolite filled thermoplastics. Upadhyay and Kale ${ }^{16,17}$ described the effects of the addition of synthetic sodium aluminum silicate (SSAS) in Nylon-6 and PP. Nylon-6 filled with up to $15 \mathrm{wt} \%$ of SSAS showed improved flexural strength and modulus. In case of flexural modulus the increment was almost double than that of virgin Nylon-6. Optical property such as yellowness index was improved with low loading of SASS, but was lowered with high content of SSAS. The similar outcome was reported for PP when it was loaded up to $40 \mathrm{wt} \%$ SSAS. Zeolite filled high density polyethylene (HDPE) composite was studied, but the most of mechanical properties such as the yield stress, the impact strength, and the elongation at break were reduced due to lowering the crystallinity and the dramatically increased air holes upon higher loading of zeolite. ${ }^{18}$

Thus, in this article, microporous composite film of LLDPE/zeolite representing a polydisperse cubic-like shape is prepared to study the followings. 1) to utilize as a potential filler source, ${ }^{19-21} 2$ ) to discover its effects on the microporous composite properties, and 3) to study dewetting and air hole formation (or crack propagation) mechanism induced by zeolite upon stretching.

\section{Experimental}

Materials. Polyolefin used in this study is linear low-density polyethylene (LLDPE; FT810) supplied by SK Corporation, Ulsan, Korea. The properties given by the supplier are as follows; density of $0.981 \mathrm{gm} / \mathrm{cm}^{3}$, melt flow index (MFI) of $2.1 \mathrm{~g} / 10 \mathrm{~min}$, and heat deflection temperature of $98^{\circ} \mathrm{C}$. Synthesized zeolite from Zeobuilder Co. Ltd., Chungnam, Korea has an average agglomerate size of $2 \sim 3 \mu \mathrm{m}$ and the pore size and the specific surface area by BET equation are $4 \AA$ and $250-350 \mathrm{~m}^{2} / \mathrm{g}$, respectively.

Zeolite Master Batch and Compounding. In order to induce better mixing between the zeolite and LLDPE, 50:50 wt\% LLDPE/zeolite master batch was previously prepared by feeding 50:50 wt\% LLDPE and dry zeolite into the hopper of a Brabender twin-screw extruder (PL 2000 ) with $L / D$ of 16 in a screw dimension. The mixed compounds extruded through a round die immediately passed through a cold-water bath, then the solidified long strands of composite were pelletized. A temperature gradient maintained in the twin-screw extruder was $170^{\circ} \mathrm{C}$ in a feeding zone, $180^{\circ} \mathrm{C}$ in a compression zone, $190^{\circ} \mathrm{C}$ in a metering zone and $200^{\circ} \mathrm{C}$ in the die. The rotation speed of the screw was maintained between 60 and $70 \mathrm{rpm}$. By controlling the amount of the master batch in pure LLDPE, from 5 to 40 wt $\%$ zeolite filled LLDPE composites were prepared.

Molding and Film Preparation. Two types of specimens, dumbbell and film type, were prepared for the measurements of mechanical properties. Dumbbell shaped sample was compression molded in a Carver laboratory hot press at $5 \times$ $10^{4} \mathrm{~Pa}$ and at $200^{\circ} \mathrm{C}$. The hot mold was allowed to naturally cool down at ambient temperature. The dimension of dumbbell bar was $13 \times 3 \times 165 \mathrm{~mm}^{3}$ following the ASTM D638M93 type M-I. Film type specimens were also prepared using a slit die in $100 \times 0.5 \mathrm{~mm}^{2}$ in dimension by fixing at the end of the extruder. Extruded sheets were uniaxially drawn using take-up device maintaining the film thickness about 400 micrometers. The dimension of the film was $15 \times 0.4 \times$ $165 \mathrm{~mm}^{3}$ according to the ASTM D882-97 for a tensile testing.

Characterization. Tensile properties of the dumbbell bar and film specimens were measured using a UTM (universal testing machine) of Instron 4465 , U. S. A., at $25^{\circ} \mathrm{C}$ and $30 \%$ humidity. Tensile properties such as yield stress, elongation at break, and maximum stress were enumerated from a stressstrain (S-S) curve. The Young's modulus as a measure of stiffness was determined from the initial slope of the S-S curve. The initial grip distance was maintained $50 \mathrm{~mm}$ and the strain rates varied between 5 and $50 \mathrm{~mm} / \mathrm{min}$ for dumbbell bar and between 50 and $500 \mathrm{~mm} / \mathrm{min}$ for film specimens.

The slow strain rate at $5 \mathrm{~mm} / \mathrm{min}$ and an initial grip distance $2 \mathrm{~mm}$ were employed for morphological study. Dewetting and the variance of the air holes between the filler and the matrix were investigated. The draw ratio was varied from 50 to maximum stretching according to each sample's ultimate behavior.

The complex melt viscosity of the pure LLDPE and zeolite filled composites was measured using a Torsion Rheometer Mk III of Polymer Laboratory, Great Britain. The complex viscosity of the samples was measured in a parallel plate $(D=38 \mathrm{~mm})$ over a frequency range of 0.03 to $200 \mathrm{rad} / \mathrm{sec}$ and the constant strain rate of $4 \%$. The round $2 \mathrm{~mm}$ thick specimens were compression molded from a hot press at $200^{\circ} \mathrm{C}$. Prior to be molded, the pelletized samples were kept in a vacuum oven at $110^{\circ} \mathrm{C}$ for $6 \mathrm{hrs}$ to prevent from the moisture absorption.

Dispersion of filler and filler agglomeration in the matrix was visualized from the cryogenically fractured surface. The stretched surface of the composite films was analyzed using a Scanning Electron Microscope (SEM), Hitachi S4300, Japan. All the specimens prepared for SEM analysis were coated with platinum using a sputter coater prior to test in SEM.

The crystallinity variance between the pure LLDPE and the zeolite filled composite was characterized using X-ray diffractometer of Philips PW 3719, USA, with a scintillation 
counter (Philips Corp., USA). Then the scanning curves for the values of $2 \theta$ ranging from 5 to 35 degree for $60 \times 40-\mathrm{mm}^{2}$ films were obtained. The incident beam $(\mathrm{CuK} \alpha, 50 \mathrm{kV}$, $25 \mathrm{~mA}$ ) was passed through Ni-filter and the pulse height discriminator was used to achieve further monochromatisation at $0.08 \% \mathrm{sec}$ of the scanning rate.

Izod impact strength were evaluated on notched samples on a CEAST instrument of Italy according to ASTM D 256 with a notch depth of $2.5 \mathrm{~mm}$ and a notch angle of $45^{\circ}$. Pure LLDPE, as well as its composites with zeolite, at least ten specimens were tested at ambient temperature and the average values were collected.

\section{Results and Discussion}

Dispersion of Zeolite. Figure 1(a) exhibits the SEM microphotographs of zeolite, which looks fairly spherical type with $2 \sim 3 \mu \mathrm{m}$ of average agglomerate size. In order to confirm the uniform dispersion of zeolite particles in the LLDPE composite, SEM microphotographs of the cryogen-
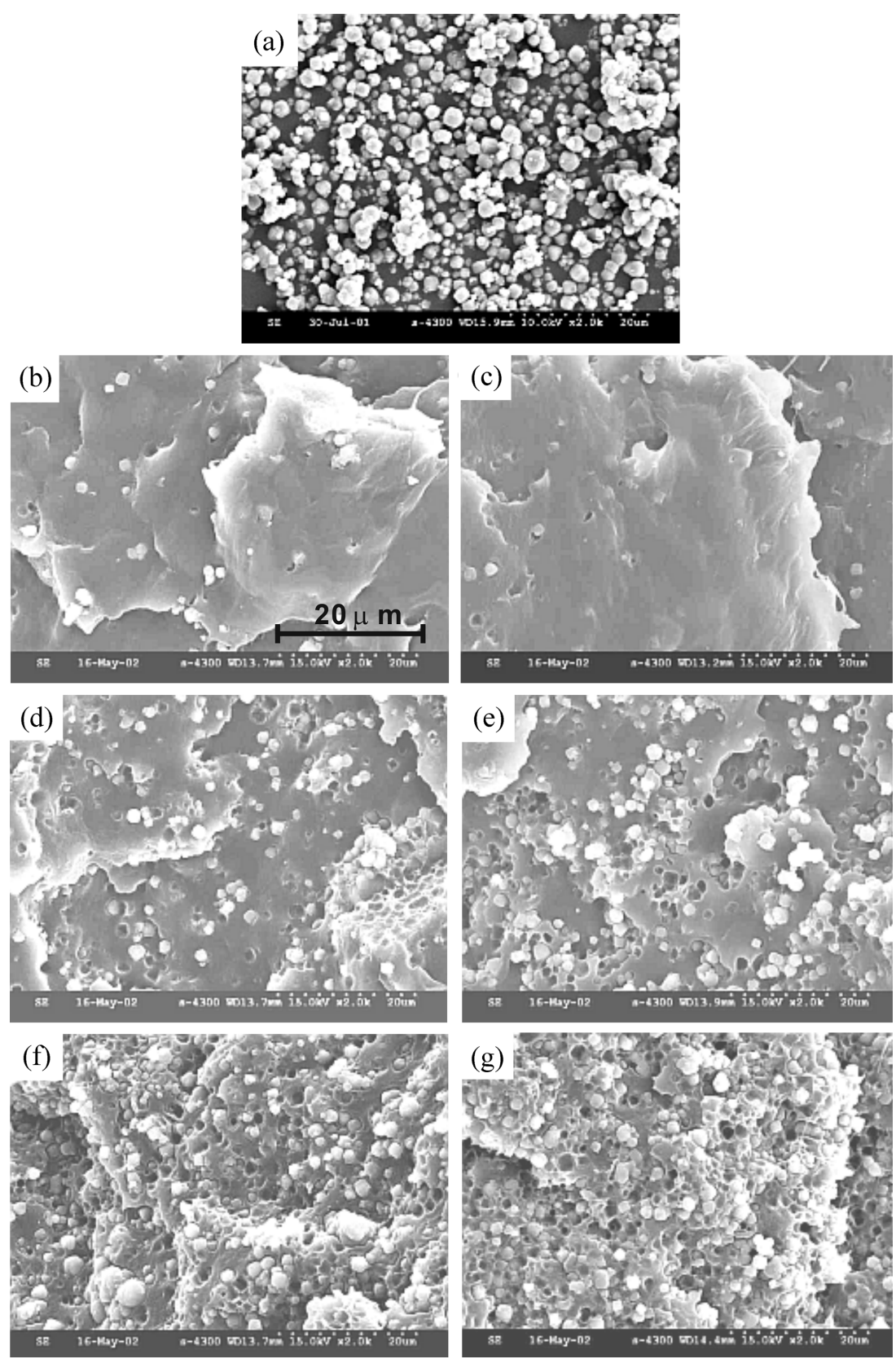

Figure 1. SEM microphotographs $(\times 2000)$ of zeolite and cryogenically fractured surface of zeolite filled LLDPE as a function of zeolite content (wt\%). (a) zeolite, (b) 5, (c) 10, (d) 20, (e) 30, (f) 40, and (g) 50 . 


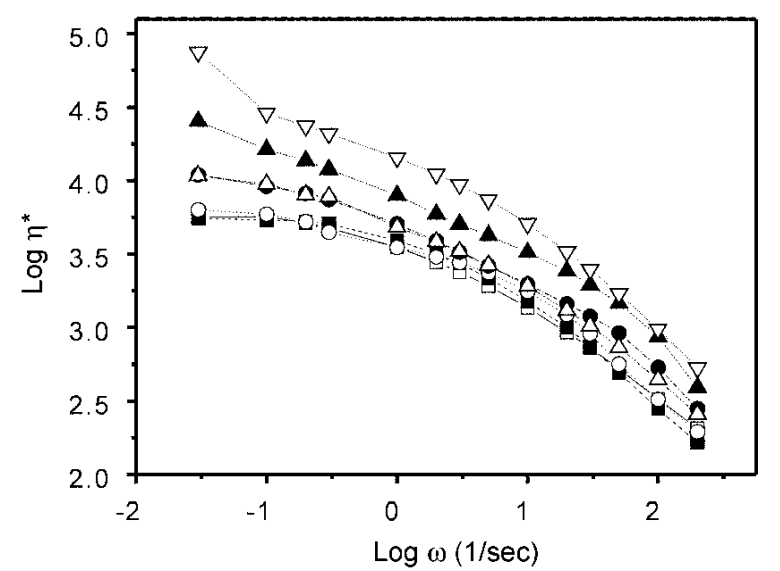

Figure 2. Complex melt viscosities of pure and zeolite filled LLDPE composites at $200^{\circ} \mathrm{C}$. ( $\square$ : Pure LLDPE; $\square$ : $5 \%$ zeolite; $\bigcirc: 10 \%$ zeolite; : $20 \%$ zeolite; $\triangle: 30 \%$ zeolite; $\boldsymbol{\Delta}: 40 \%$ zeolite; $\nabla: 50 \%$ zeolite).

ically fractured surface of the samples were taken as seen in Figure 1. A good dispersion of zeolite in LLDPE was achieved and this seems to be discrete without any agglomeration. Thus, a fair adhesion between zeolite and LLDPE and thereafter a good wetting of the filler into matrix were suggested.

Rheology. The complex melt viscosities $\left(\eta^{*}\right)$ of pure LLDPE and the zeolite filled system are plotted in Figure 2 in terms of frequency. The complex viscosity decreases with increasing frequency for both the pure and zeolite filled LLDPE, showing a typical non-Newtonian behavior. As the zeolite content increased, the complex melt viscosity gradually increased up to $30 \mathrm{wt} \%$ zeolite, but at 40 and $50 \mathrm{wt} \%$ zeolite filled one, the viscosity abruptly increased with slight yielding behavior at low frequency. The yielding behavior that is often induced by a strong interaction between filler and polymer matrix when active filler is suspended in a polymer matrix. ${ }^{22-24}$

Tensile Properties. In order to compare the tensile properties of the pure and zeolite filled LLDPE composites, two types of specimens are prepared, dumbbell and film type. Figure 3 exhibits the stress-strain curves of the pure LLDPE and zeolite filled composites in dumbbell bar measured at the strain rates of $5 \mathrm{~mm} / \mathrm{min}$ (Figure $3 \mathrm{a}$ ) and $50 \mathrm{~mm} / \mathrm{min}$ (Figure $3 b$ ). It should be noted that the pure LLDPE and majority of its composite specimens are not broken up to the elongation limit of the machine (which means that the machine can stretch the sample for a span of $20 \mathrm{~min}$ ). Clearly, it is seen that the stress increases with the zeolite concentration and this may be due to a reinforcement effect. At $50 \%$ of zeolite loading, the elongation at break was observed 11 and $16 \%$ for 5 and $50 \mathrm{~mm} / \mathrm{min}$ of strain rate, respectively. In particular, the yielding behavior was observed for the 40 and $50 \mathrm{wt} \%$ of zeolite filled dumbbell bar at $50 \mathrm{~mm} / \mathrm{min}$. In our
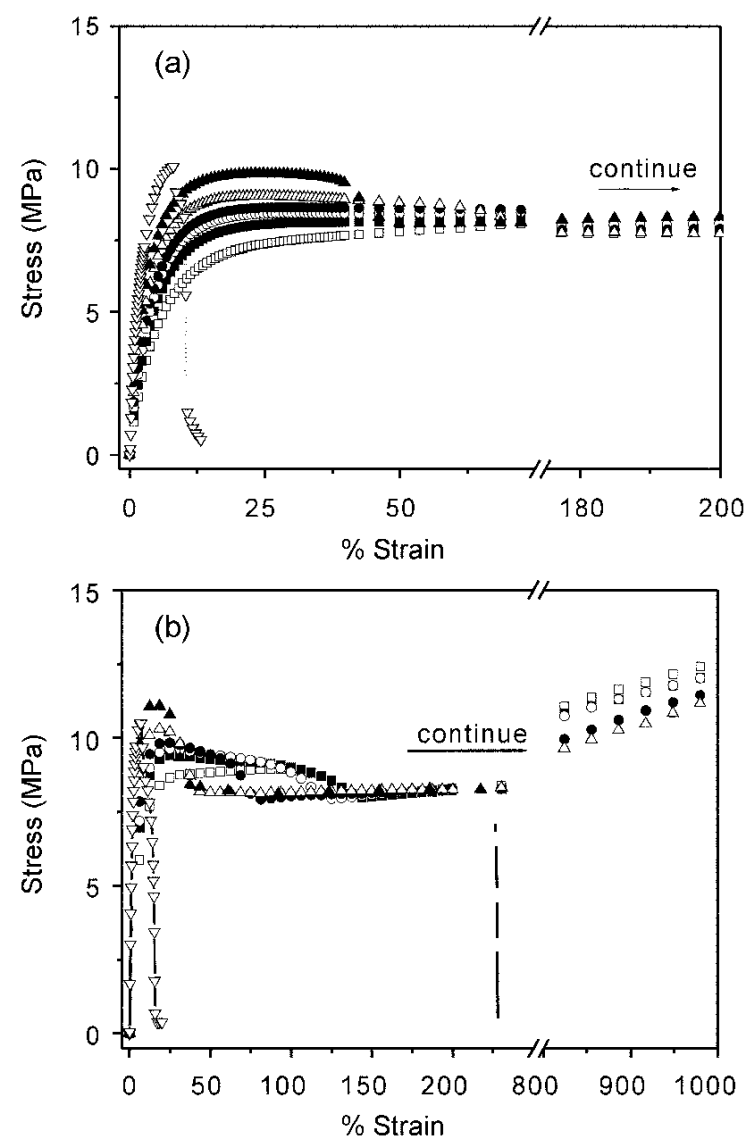

Figure 3. Stress-strain curves of dumbbell bars for pure and zeolite filled LLDPE composites at crosshead speeds of (a) 5 and (b) 50 $\mathrm{mm} / \mathrm{min}$ (the symbols are the same as in Figure 2).

previous study, ${ }^{11} 50 \mathrm{wt} \%$ of calcite filled LLDPE dumbbell bar yielded 42 and $12 \%$ strain at 5 and $50 \mathrm{~mm} / \mathrm{min}$, respectively.

Figures 4(a) and 4(b) exhibit the stress-strain curves of the film for pure LLDPE and various compositions of zeolite filled LLDPE at 50 and $500 \mathrm{~mm} / \mathrm{min}$, respectively. It is interesting that strain rate dependent stress is not observed in this system, but the yielding behavior is observed for all of the compositions. The elongation at break exceeds $1000 \%$ (machine limit; which means the machine can elongates the sample up to $500 \mathrm{~mm}$ ) for pure LLDPE through $30 \mathrm{wt} \%$ zeolite filled film at $50 \mathrm{~mm} / \mathrm{min}$, then declines to $931 \%$ for $40 \mathrm{wt} \%$ and $143 \%$ for $50 \mathrm{wt} \%$ zeolite filled one. In addition, at $500 \mathrm{~mm} / \mathrm{min}$, similar behavior is observed up to $40 \mathrm{wt} \%$ filled composite, but it is extremely reduced to $67 \%$ of elongation for $50 \mathrm{wt} \%$ of zeolite loading. This behavior is almost the same as HDPE/zeolite system except $50 \mathrm{wt} \%$ zeolite filled one; $630 \%$ at $50 \mathrm{~mm} / \mathrm{min}$, and $401 \%$ at $500 \mathrm{~mm} /$ min, respectively. ${ }^{18}$

The Young's modulus that is a characteristic of material's rigidity is observed in Figure 5; for pure LLDPE,162 and $173 \mathrm{MPa}$ are obtained for 5 and $50 \mathrm{~mm} / \mathrm{min}$, respectively. 

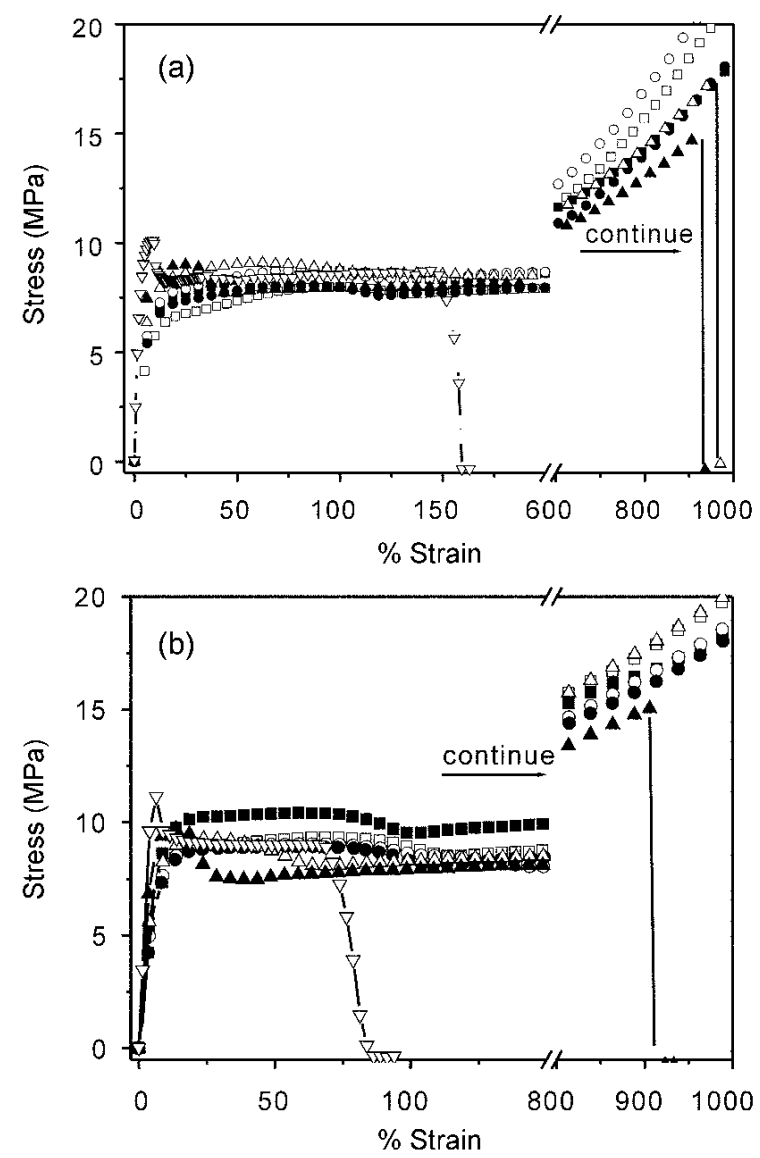

Figure 4. Stress-strain curves of film specimens for pure and zeolite filled LLDPE composites at crosshead speeds of (a) 50 and (b) $500 \mathrm{~mm} / \mathrm{min}$ (the symbols are the same as in Figure 2).

By increasing filler loading from 5 to $50 \mathrm{wt} \%$, a corresponding progressive modulus increased by a 2.5 times from 198 to $496 \mathrm{MPa}$ at $5 \mathrm{~mm} / \mathrm{min}$ (Figure $5 \mathrm{a}$ ). Similarly, the modulus increased from 238 to $530 \mathrm{MPa}$ at $50 \mathrm{~mm} / \mathrm{min}$ (Figure 5a). However, the Young's modulus is not affected by the crosshead speed during the tensile test using dumbbell specimen. In addition, the Young's modulus of the film specimen increased by 3.5 times from 120 to $417 \mathrm{MPa}$ for $50 \mathrm{~mm} / \mathrm{min}$, and from 127 to $179 \mathrm{MPa}$ for $500 \mathrm{~mm} / \mathrm{min}$ (Figure 5b). The slope of the modulus increment is higher in $50 \mathrm{~mm} / \mathrm{min}$ than in $500 \mathrm{~mm} / \mathrm{min}$, as usual. Since the modulus is calculated from the initial slope of the $\mathrm{S}-\mathrm{S}$ curve, the modulus calculated at $500 \mathrm{~mm} / \mathrm{min}$ would not accurate due to fast elongation.

Two common equations that are frequently used to estimate the modulus of particle-filled composites are ${ }^{25}$ :

$$
\begin{aligned}
& M_{c}=M_{p} \phi_{p}+M_{f} \phi_{f} \\
& M_{c}=\frac{M_{p} M_{f}}{M_{p} \phi_{f}+M_{f} \phi_{p}}
\end{aligned}
$$

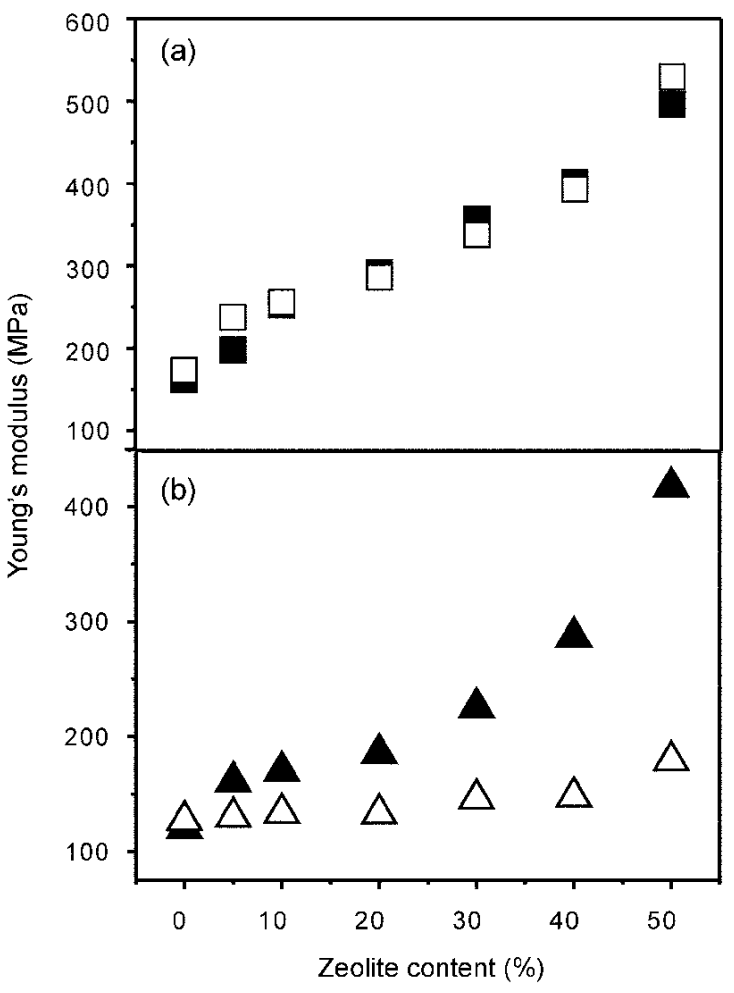

Figure 5. The Young's modulus of pure and filled LLDPE dumbbell and film at various crosshead speeds. (a) dumbbell $5 \mathrm{~mm} / \mathrm{min}$; $\square: 50 \mathrm{~mm} / \mathrm{min}$ ) and (b) film ( $\Delta: 50 \mathrm{~mm} / \mathrm{min} ; \triangle$ : $500 \mathrm{~mm} / \mathrm{min}$ ).

where, $M_{c}$ is the modulus of the composite, $M_{p}$ and $M_{f}$ are the moduli of the polymer matrix and filler, respectively, $\phi_{p}$ and $\phi_{f}$ are the volume fraction of the polymer and filler, respectively. Eq. (1) is appropriate when strong adhesion exist between the filler and polymer and the filler has higher aspect ratio, where as Eq. (2) is applicable to rigid spherical particles.

The modulus of the zeolite is extrapolated by putting the experimental modulus and the volume fraction of the filler, of which the modulus of zeolite yields 2,700 MPa. In the case of this system, since the zeolite used as the filler is closer to spherical shape, the Eq. (2) is expected to logically fit for the experimental results. But as shown in Figure 6, the experimental modulus is between the Eqs. (1) and (2).

The yield stress and the elongation at break for the pure and zeolite filled LLDPE composites in dumbbell and film types at various crosshead speeds are analyzed in Figure 7. The yield stress measured for the pure LLDPE at 5 and $50 \mathrm{~mm} / \mathrm{min}$ are 6.8 and $9.5 \mathrm{MPa}$, respectively. In the case of dumbbell bar, the yield stress for the composites continuously increases from 7.5 to $10.1 \mathrm{MPa}$ and 9.4 to $11.1 \mathrm{MPa}$ for 5 and $50 \mathrm{~mm} / \mathrm{min}$, respectively. The augmentation of yield stress with zeolite indicates the reinforcement introduced by the incorporation of zeolite. In film type specimen, the yield 
stress also progressively increases with zeolite content, but is lower than that of the dumbbell shape at the same crosshead speed.

The elongation at break for dumbbell bar is larger than $1000 \%$ (which mean that machine can stretch the sample for

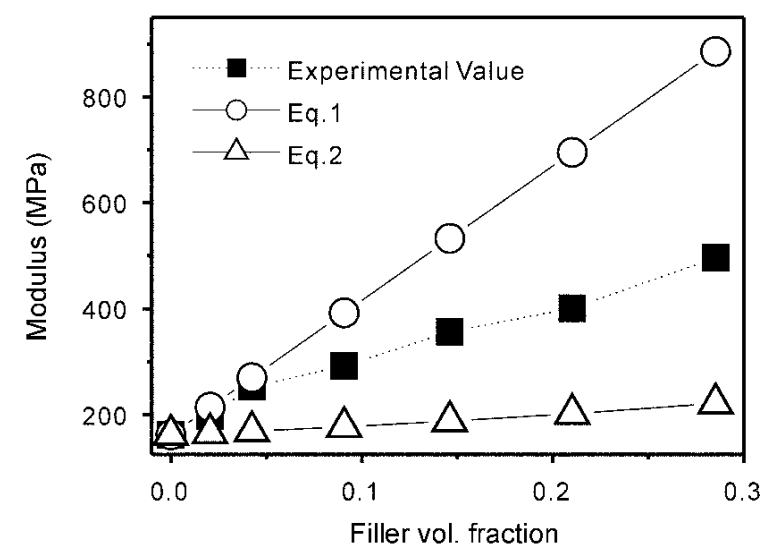

Figure 6. The calculated and experimental moduli of the zeolite filled LLDPE composite as a function of filler contents on dumbbell specimen at $5 \mathrm{~mm} / \mathrm{min}$. The modulus of the zeolite is taken to be $2,700 \mathrm{MPa}$.

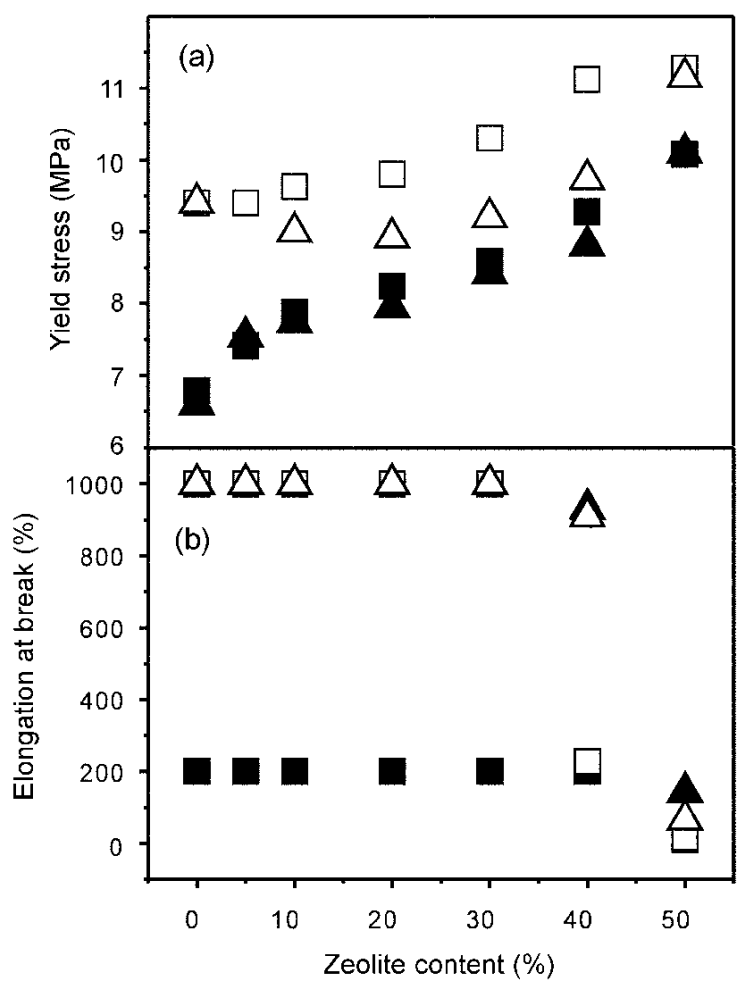

Figure 7. Yield stress and elongation at break of pure and zeolite filled LLDPE composite on dumbbell (square symbol) and film (triangle symbol) $(\boldsymbol{\square}: 5 \mathrm{~mm} / \mathrm{min} ; \square: 50 \mathrm{~mm} / \mathrm{min} ; \boldsymbol{\Delta}: 50 \mathrm{~mm} /$ min; $\triangle: 500 \mathrm{~mm} / \mathrm{min}$ ). (a) yield stress and (b) elongation at break. a span of $20 \mathrm{~min}$ ) for loadings up to $30 \mathrm{wt} \%$ zeolite at $50 \mathrm{~mm} / \mathrm{min}$. Then it dramatically decreases to $228 \%$ and $16 \%$ for 40 and $50 \mathrm{wt} \%$ zeolite filled composites, respectively. We observed that the similarity of breakage of $50 \mathrm{wt} \%$ zeolite filled dumbbell specimen at $5 \mathrm{~mm} / \mathrm{min}$ yielded just $12 \%$ elongation, whereas all other compositions continued up to the machine limit. In the case of 50\% calcite filled PE film, the elongation at break was $650 \%$ and $510 \%$ at the crosshead speeds of 50 and $500 \mathrm{~mm} / \mathrm{min}$, respectively. ${ }^{10}$

Impact Properties. Figure 8 is the representation of the impact strength of both the pure and filled system (error bar indicates the experimental deviation). The impact strength of the composites up to $40 \%$ zeolite is higher than that of pure LLDPE. However as the loading exceeds a critical concentration, the composites gradually lose their high impact ductile character. The $50 \%$ zeolite filled composite shows dramatic decrease in impact strength and implies that the tendency of brittleness of the material has a correspondence to the poor yield stress and elongation at break. Thus, up to an optimum filler loading, the composites may be applicable for breathable microporous films with improved modulus, impact and yield stress, elongation at break properties.

Mechanism of Air-hole Formation and Its Growth. In order to study the dewetting, followed by the formation and growth of air holes upon stretching, two representative films, which are 5 and $40 \mathrm{wt} \%$ zeolite filled composite were stretched up to a certain level of strain. Figure 9 shows the air hole formation and its growth (or propagation) for $5 \mathrm{wt} \%$ zeolite filled LLDPE composite. At $50 \%$ of strain, dewetting between the zeolite particles and the LLDPE matrix is first introduced. As the applied strain increases, the previously dewetted areas act as loci of air hole growth as seen at higher strains up to $300 \%$. The size of the air hole increases in elliptical shape and the population density of the cavities also increases with the strain ratio.

On the other hand at $40 \mathrm{wt} \%$ of zeolite filled LLDPE com-

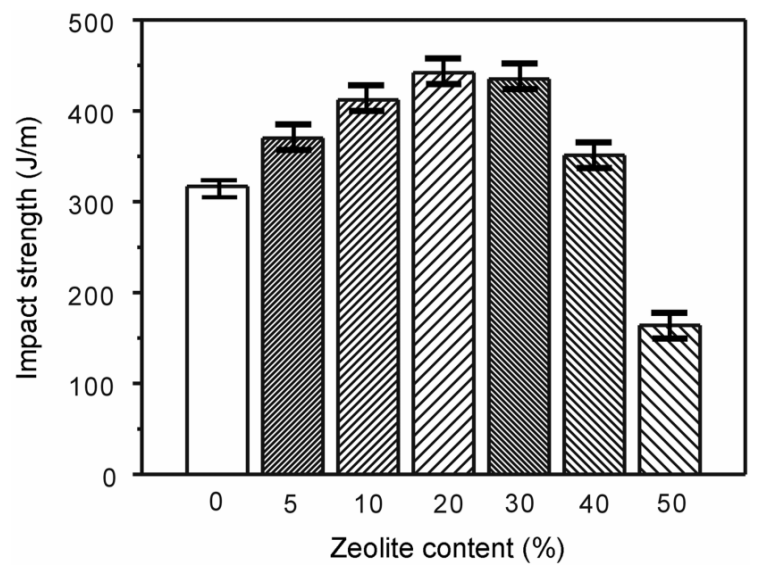

Figure 8. Impact properties of the pure and LLDPE composites system at room temperature (error bars represent the experimental deviations). 

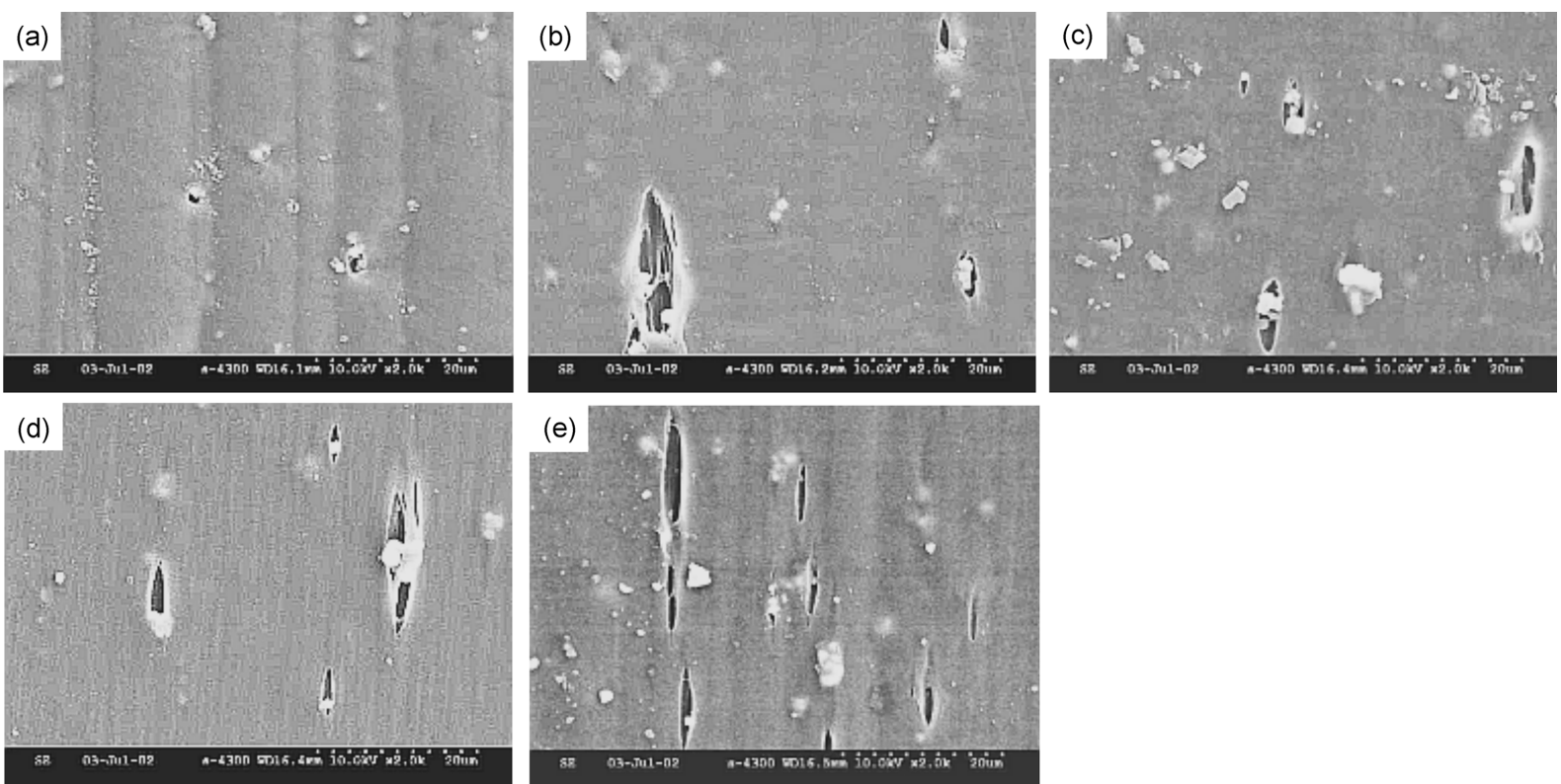

Figure 9. SEM microphotographs $(\times 2000)$ of $5 \mathrm{wt} \%$ zeolite filled LLDPE film at various draw ratios and at a crosshead speed of 5 $\mathrm{mm} / \mathrm{min}$ with an initial gap distance of $2 \mathrm{~mm}$. (a) $50 \%$, (b) $100 \%$, (c) $200 \%$, (d) $300 \%$, and (e) $400 \%$.
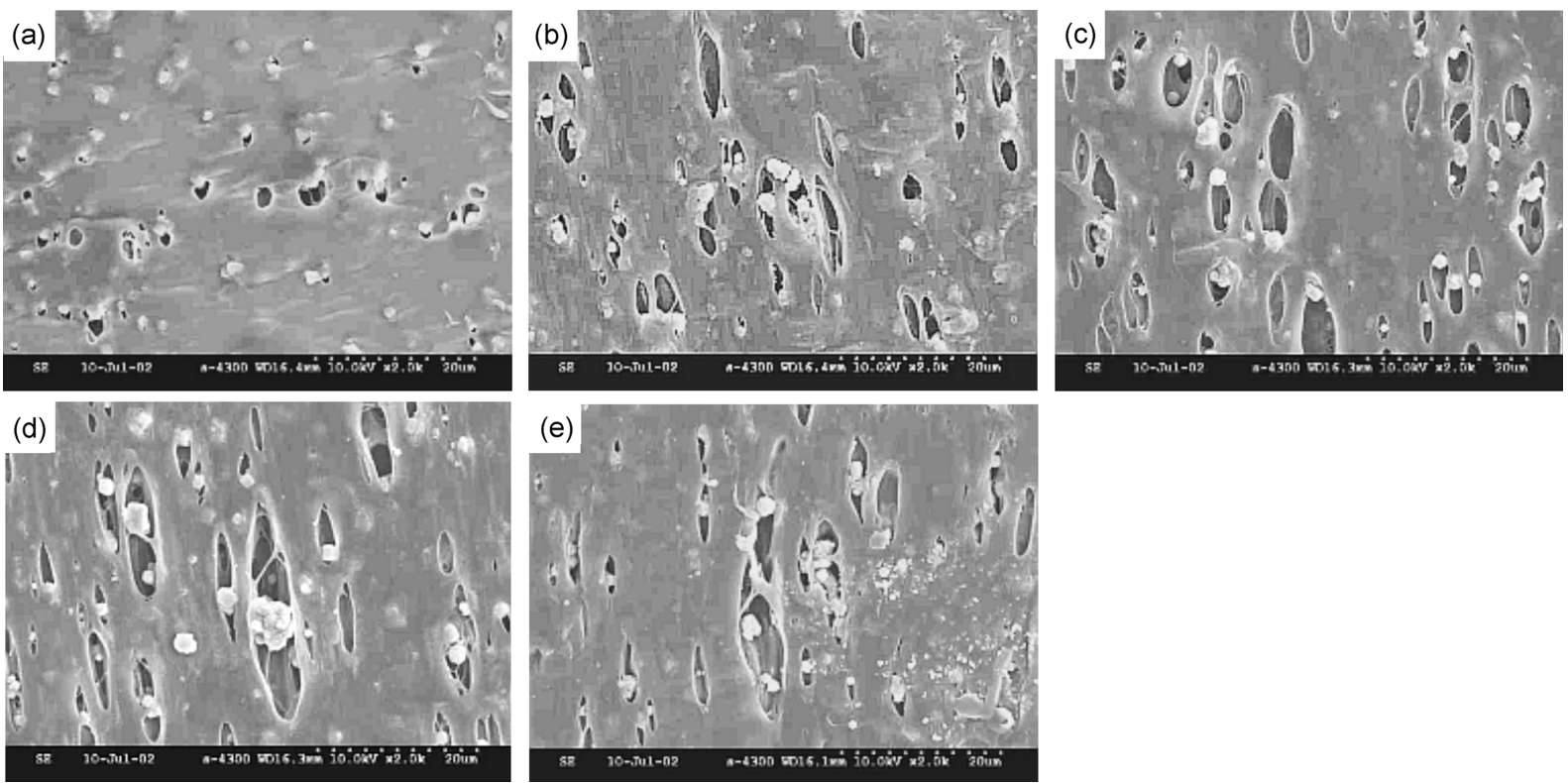

Figure 10. SEM microphotographs $(\times 2000)$ of $40 \mathrm{wt} \%$ zeolite filled LLDPE film at various draw ratios and at a crosshead speed of 5 $\mathrm{mm} / \mathrm{min}$ with an initial gap distance of $2 \mathrm{~mm}$. (a) $50 \%$, (b) $100 \%$, (c) $200 \%$, (d) $300 \%$, and (e) $400 \%$.

posite as seen in Figure 10, the formation and its growth of air holes are rather obvious. The number of dewetting sites and the increase of the air hole areas due to high loading of zeolite are distinctly visible. At the initial stage of stretching at $50 \%$, the air holes formed by dewetting was round shape, but the final stage of stretching at $400 \%$, the air holes enlarge due to the merging of the nearest air holes and the breaking of the neighboring fibril structure. The average size of the air holes are in the range of $3 \sim 30$ microns and the average aspect ratio increases from 2.63 to 4.43 from 100 to $400 \%$ of stretching.

According to Kwon et al., ${ }^{10}$ they worked on the $50 \mathrm{wt} \%$ stearic acid coated calcite filled LLDPE, HDPE, and LDPE systems. The elongation at break at $50 \%$ calcite filled LLDPE film was $650 \%$ at a crosshead speed of $50 \mathrm{~mm} / \mathrm{min}$. In addition, the $50 \mathrm{wt} \%$ calcite filled LLDPE film also 

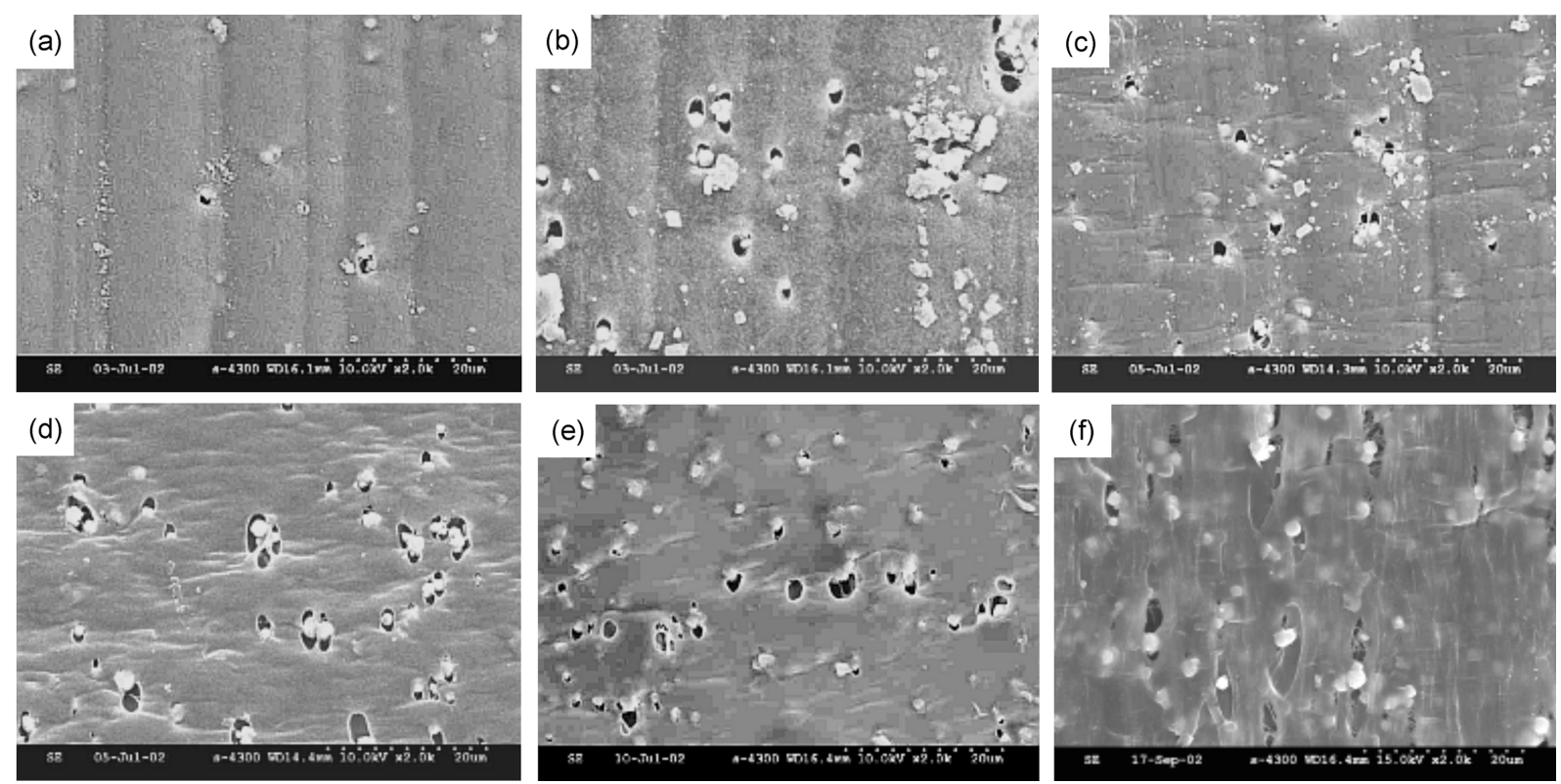

Figure 11. SEM microphotographs $(\times 2000)$ of $50 \%$ stretched film as a function of zeolite content (wt $\%)$. (a) $5 \%$, (b) $10 \%$, (c) $20 \%$, (d) $30 \%$, (e) $40 \%$, and (f) $50 \%$.
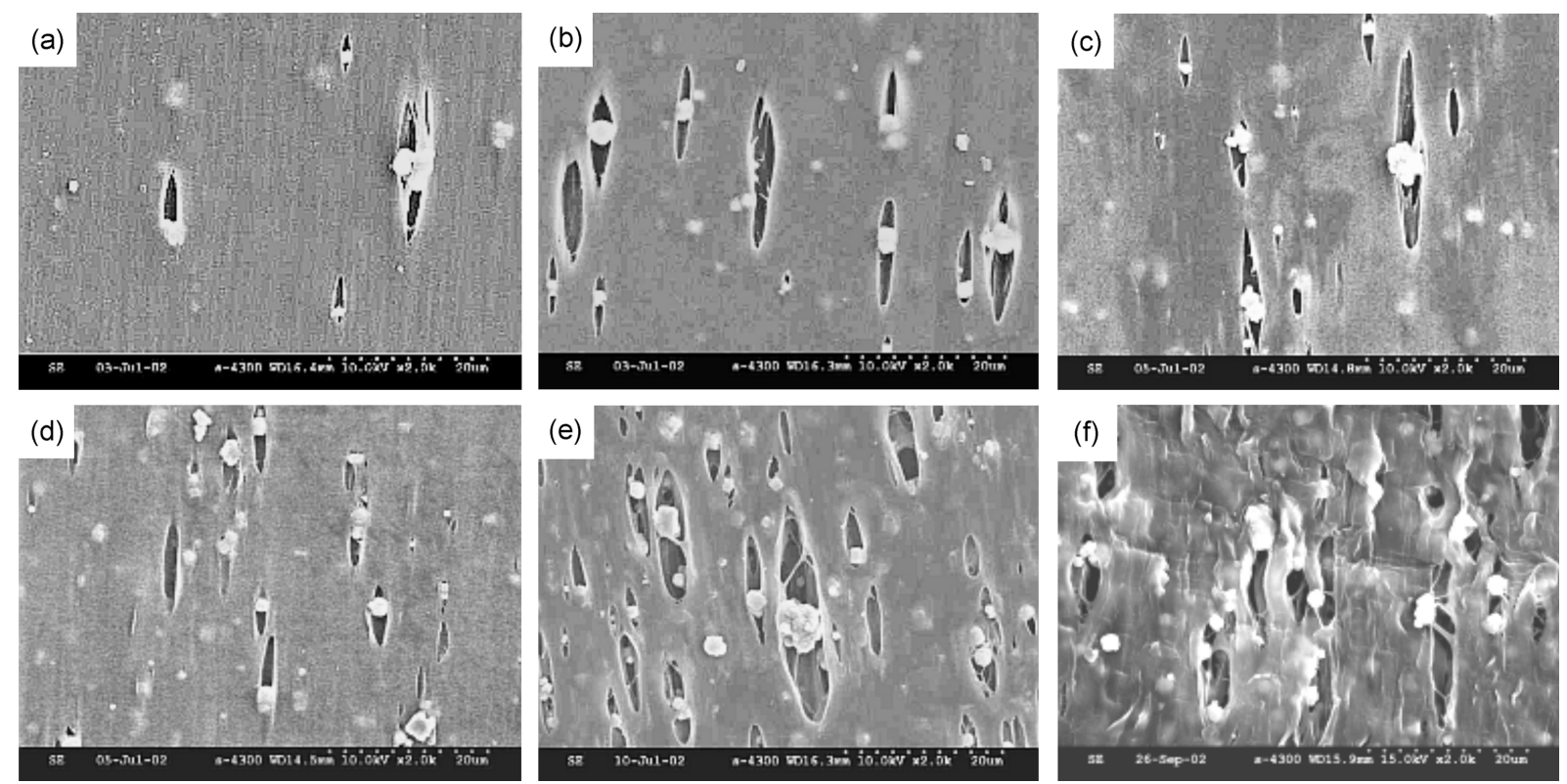

Figure 12. SEM microphotographs $(\times 2000)$ of $300 \%$ stretched film as a function of filler content (wt $\%$ ). (a) $5 \%$, (b) $10 \%$, (c) $20 \%$, (d) $30 \%$, (e) $40 \%$, and (f) $50 \%$.

showed the simultaneous formation of air holes along the machine direction (MD).

The mechanism of the dewetting, air hole formation and its growth is discussed precisely in our previous report, ${ }^{11,12}$ where the well dispersed and wetted calcite particles in LLDPE matrix were dewetted first upon stretching at low level. As the draw ratio increased, the formation of fibril structure appeared with the simultaneous growth of air holes. Subse- quently the size of air holes enlarged by breaking the fibril structure and by the merging of neighboring air holes. Hyun et al. also reported ${ }^{11}$ a similar observation in $50 \mathrm{wt} \%$ calcite filled polypropylene (PP), poly(propylene-co-ethylene) (CoPP), and poly(propylene-co-ethylene-co-1-butene) (TerPP) systems.

Figure 11 is the comparison of $50 \%$ stretched films for the studied compositions in the present system. The dewetting 
nature is almost identical between the filler and matrix from 5 to $50 \%$ of zeolite content. In addition, the number of dewetting zone increases with the filler content. In particular, in Figures 11(c), (d), (e), where the zeolite contents are 20, 30, and $40 \mathrm{wt} \%$, respectively, the crazing along the machine direction is ob-served. In Figures 12(a) through 12(e), the SEM photographs of $300 \%$ stretched films from 5 to $40 \%$ zeolite loading are exhibited. Exception is shown in Figure 12(f), where $50 \%$ zeolite filled composite film elongates only $67 \%$. In addition, many of air holes hold agglomerated or discrete form of zeolite particles along the machine direction (MD). As a consequence, the bigger air holes can be formed by not only the agglomerated zeolite particles, but also the merging phenomenon of the neighboring air holes due to breaking the fibril structure.

Figures 13(a)-(c) represent the comparative values of the aspect ratio, the number of air-holes, and total area of air-holes, respectively, due to various contents of zeolite and draw ratios. In Figure 13(a), the values of the aspect ratio gradually increase with increasing draw ratio, on the other hand, the content of filler doesn't remarkably influence on it. This is comparable with HDPE system, where the air holes dramatically increased with draw ratio due to the fibrous breaking and simultaneous merging effect originated from the structural difference. ${ }^{18}$ The number of air holes as plotted in Figure 13(b) showed the maximun at $40 \%$ of zeolite content, but then abruptly decreased at $50 \%$ zeolite filled LLDPE composite. As expected, there is no considerable effect of draw ratio on the number of air holes. In Figure 13(c) representing the total area of air holes according to the zeolite content and draw ratio, no significant increase on the total area of air holes was observed up to $30 \%$ filled system, but at $40 \%$ zeolite filled LLDPE composite, the total area dramatically increased at $300 \%$ draw ratio.

Table I shows the tabulated values of pore size, maximum air-hole size and microporosity in stretched film, which was determined by Image analyzer program on SEM photographs.

Wide Angle X-ray Diffraction. Figures 14(a) and (b) represent the intensity vs. $2 \theta$ between 5 and 35 degrees, and the strong peak area between 20 and 25 degree of $2 \theta$, respectively. As seen in Figure 14(a), pure LLDPE exhibited the main peak at 21.7 and 24.2 of $2 \theta$ depicting 110 and 200 reflections without any noticeable noise. However, the highest

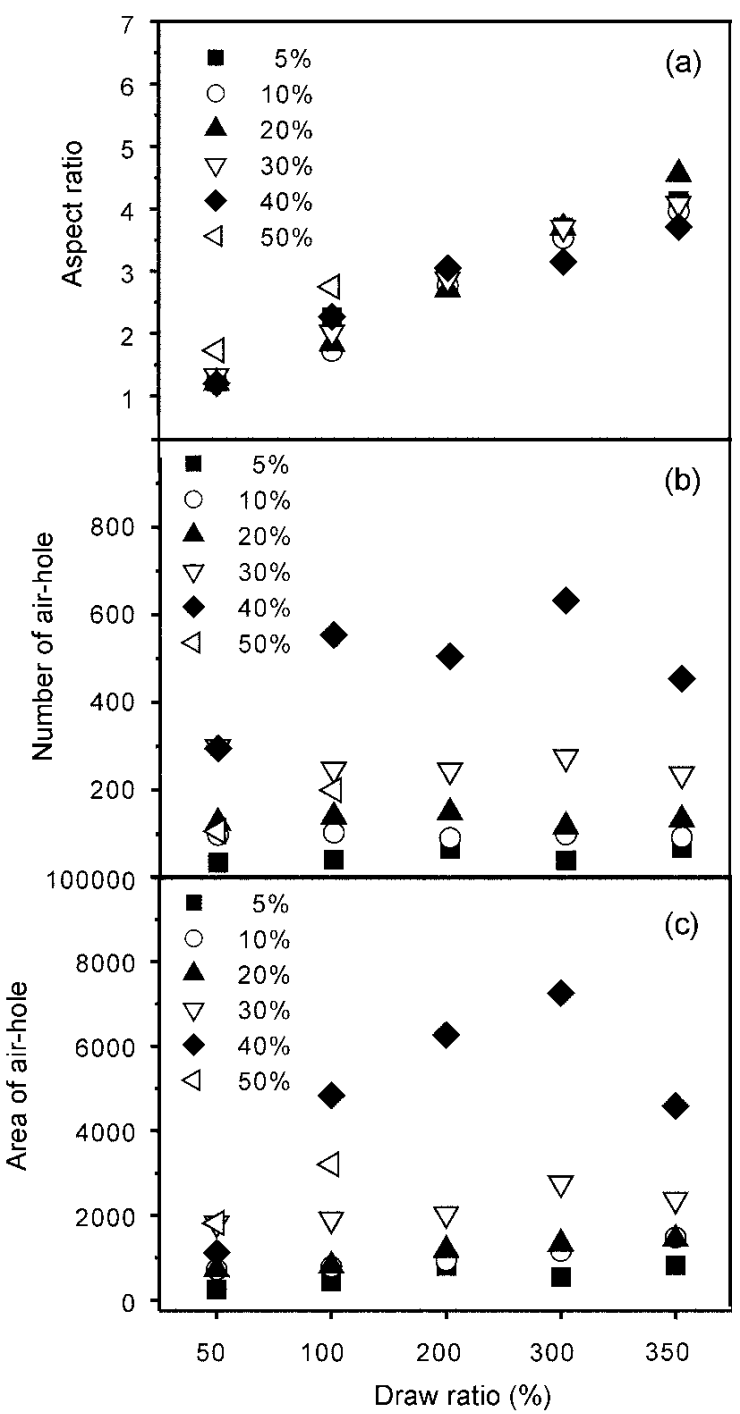

Figure 13. The comparison of the various values on the aspect ratio, the number and the total area of air holes at various contents of zeolite and draw ratios during stretching. (a) Aspect ratio, (b) The number of air holes, and (c) Total area of air holes.

peak intensities at 21.7 of $2 \theta$ for the pure, 5, 10, 20 and 30 wt $\%$ zeolite filled composites are all remained unaffected, but then abruptly decreased for 40 to $50 \mathrm{wt} \%$ zeolite filled ones as seen in Figure 14(a). This implies that no big differ-

Table I. The Comparison of the Various Values on Air-holes in SEM Photographs at the Different Zeolite Content Ratios and 50 and $300 \%$ Draw Ratios

\begin{tabular}{lccccccccccc}
\hline \multicolumn{1}{c}{ Zeolite Content } & \multicolumn{2}{c}{$5 \%$} & \multicolumn{2}{c}{$10 \%$} & \multicolumn{2}{c}{$20 \%$} & \multicolumn{2}{c}{$30 \%$} & \multicolumn{2}{c}{$40 \%$} & $50 \%$ \\
\hline Drew Ratio $(\%)$ & 50 & 300 & 50 & 300 & 50 & 300 & 50 & 300 & 50 & 300 & 50 \\
Average Pore Size $\left(\mu \mathrm{m}^{2}\right)$ & 7.1 & 13.6 & 7.3 & 11.7 & 5.8 & 11.4 & 6.1 & 10.0 & 3.8 & 11.4 & 17.1 \\
$\begin{array}{l}\text { Maximum Size of Air Hole } \\
\left(\mu \mathrm{m}^{2}\right)\end{array}$ & 32.4 & 57.1 & 45.7 & 46.7 & 25.9 & 149 & 25.6 & 76.7 & 16.0 & 130 & 66.6 \\
Porosity $(\%)$ & 0.57 & 1.24 & 1.64 & 2.65 & 1.65 & 3.04 & 4.14 & 6.29 & 2.55 & 16.5 & 4.15 \\
\hline
\end{tabular}



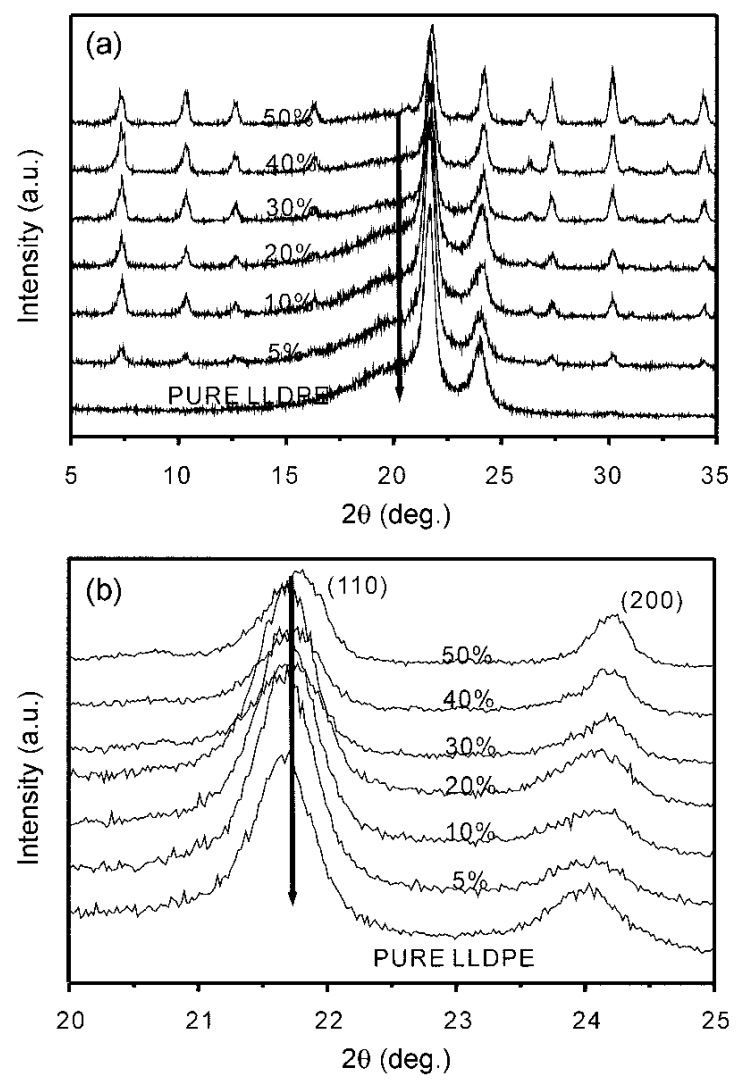

Figure 14. XRD plot of pure LLDPE and zeolite filled LLDPE composites. (a) $2 \theta: 5^{\circ}-35^{\circ}$ and (b) $2 \theta: 21^{\circ}-23^{\circ}$.

ence in crystallinity between the pure and up to $30 \mathrm{wt} \%$ filled LLDPE composite is observed, whereas dramatic reduction in crystallinity upon incorporation of 40 and $50 \mathrm{wt} \%$ of zeolite is observed. Thus the presence of zeolite affected not only the degree of crystallinity, but also the mechanical properties such as the reduced yield stress and Izod impact strength. Mechanical and SEM photographs of PP/nanocomposite with calcite are slightly different from our results. ${ }^{25}$ In the presence of zeolite, however, the peak located at 24.2 of $2 \theta$ is slightly moved to 24.4 with 200 reflection.

\section{Conclusions}

The LLDPE/zeolite composites were prepared by a conventional compounding procedure using a twin-screw extruder. Mechanical properties of pure LLDPE and its composites having various amounts of zeolite are thoroughly analyzed using dumbbell and film type specimens. Improved mechanical properties in terms of the Young's modulus, the yield stress, the impact strength and the elongation at break were observed up to $40 \mathrm{wt} \%$ zeolite filled LLDPE composites. The complex melt viscosity of the composites sequentially increases with the additional zeolite loading. In addition, the yielding behavior in terms of viscosity is observed for 40 and
$50 \mathrm{wt} \%$ filled system at low frequency. The dispersion of zeolite in the matrix and dewetting between the matrix and filler upon stretching are investigated using a Scanning Electron Microscopy (SEM) photographs. The observed dispersion of filler in the matrix shows a good adhesion between them. The dewetting and a simultaneous formation of air holes between the filler and the matrix indicate an optimistic result for producing microporous structure of the composites. The dewetted zones in the film at low strain grow to form elliptical micropores for further stretching. The aspect ratio gradually increases with the draw ratio, but is not remarkably influenced with filler content. The number of air holes increases with filler loading and showed maximum at $40 \%$ zeolite loading, but does not affect by the draw ratio. Finally, the total area of air holes according to the zeolite content and draw ratio does not significantly increase up to $30 \%$ filled system, but at $40 \%$ zeolite filled LLDPE with $300 \%$ draw ratio exhibited the maximum properties. Thus $40 \%$ zeolote filled LLDPE composite with 300\% elongation may be applicable for breathable microporous films with improved modulus, impact and yield stress, elongation at break, and microporous properties.

Acknowledgements. This work is financially supported by the KOSEF grant No. R01-2001-000-00432-0 during the year of 2002-2003. S. Choe also thanks to Inha University for the partial financial support.

\section{References}

(1) W. R. Hale, K. K. Dohrer, M. R. Tant, and I. D. Sand, Colloid Surface A, 483, 187 (2001).

(2) L. E. Nielsen and R. F Landel, Mechanical Properties of Polymers and Composites, Marcel Dekker, New York, 1994.

(3) C. J. R. Verbeek, Mater Lett., 52, 453.(2002).

(4) S. L. Bai, J. K Chen, Z. P. Huang, and Z. D Liu, Polym Int., 50, 222 (2001).

(5) G. Wang, P. Jiang, Z. Zhu, and J. Yin, J. Appl. Polym. Sci., 85, 2485 (2002).

(6) J. Kocsis-Karger, Polypropylene Structure, Blends and Composites, Chapman \& Hall, London, 1995.

(7) E. Martuscelli, R. Palumbo, and M. Kryszewski, Polymer Blends, Plenum, New York, 1979.

(8) P. Mareri, S. Bastide, N. Binda, and A. Crespy, Compos. Sci. Technol., 58, 747, (1998).

(9) H. Z. Rozman, C. Y. Lai, H. Ismail, and Z. A. Ishakmohd, Polym. Int., 49, 1273. (2000).

(10) S. Kwon, K. J. Kim, H. Kim, P. P. Kundu, Y. W. Kim, Y. K. Lee, B. H. Lee, and S. Choe, Polymer, 43, 6901 (2002).

(11) H. Kim, K. J. Kim, S. Kwon, P. P. Kundu, B. C. Jo, Y. K. Lee, B. H. Lee, and S. Choe, J. Appl. Polym. Sci., 86, 2041 (2002).

(12) K.-J. Kim, S. Kwon, H. Kim, P. P. Kundu, Y. W. Kim, Y. K. Lee, K. J. Lee, B. H. Lee, and S. Choe, J. Appl. Polym. Sci., 87, 311 (2003).

(13) S. J. Paresh, U.S. Patent 4,777,073 (1988). 
(14) S. Nago and Y. Mizutani, J. Appl. Polym. Sci., 68, 1543 (1998).

(15) H. V. Bekkum, E. M. Flanigen, P. A. Jacobs, and J. C. Jansen, Introduction to Zeolite Science and Practice, Elsevier Science B.V, Amsterdam, Netherlands, 2001.

(16) R. D. Upadhyay and D. D. Kale, J. Appl. Polym. Sci., 81, 2297 (2001).

(17) R. D. Upadhyay and D. D. Kale, Polym. Int., 50, 1209 (2001).

(18) H. Kim, J. Biswas, H. H. Choi, B. H. Lee, and S. Choe, J. Industry and Engineering Chemistry, 9(6), 619 (2003).

(19) Y. J. Lee, J. M. Shim, and W. S. Kim, Mater. Chem. Phys., 48,
36 (1997)

(20) F. Özmihci, D. Balköse, and S. Ülkü, J. Appl. Polym. Sci., 82, 2913 (2001).

(21) B. Adnadjevic and J. Jovanovic, J. Appl. Polym. Sci., 77, 1171 (2000).

(22) A. R. Payne, J. Appl. Polym. Sci., 7, 127 (1960).

(23) A. Y. Malkin, Adv. Polym. Sci., 96, 69 (1990).

(24) J. Biswas, H. Kim, G.-J. Kim, D. S. Lee, and S. Choe, Eur. Polym. J., in press.

(25) C. -M. Chan, J. Wu, J. -X. Li, and Y. -K. Cheung, Polymer, 43, 2981 (2002). 